\title{
O PRINCÍPIO DA FUNÇÃO SOCIAL EM CONSONÂNCIA COM ATIVIDADE EMPRESARIAL
}

\section{THE PRINCIPLE OF SOCIAL FUNCTION IN CONNECTION WITH BUSINESS ACTIVITY}

\author{
Helen Samara da Silva Costa ${ }^{1}$ \\ Helena Beatriz de Moura Belle ${ }^{2}$
}

Resumo: Neste artigo tem-se por intuito expor, analisar e compreender a importância e a viabilidade da atuação e a exploração da atividade empresarial em consonância com os princípios constitucionais que tratam da função social, da justiça social, da valorização do trabalho humano, da existência digna e do desenvolvimento social nacional. $\mathrm{O}$ estudo se efetuou com base em pesquisa bibliográfica, mediante técnica em exame de doutrinas e artigos científicos especializados no assunto e na legislação pertinente. Constatou-se que a atividade empresarial, em geral, vem ocorrendo com o fim exclusivo de alcançar o lucros; os interesses particulares de investidores de capitais são colocados acima dos interesses coletivos, o que contribui para o aumento da desigualdade social. Situação que vem se perpetuando no ambiente mercantil muitas vezes por falta da aplicação da lei de forma rigorosa pelo Estado.

Palavras-Chave: Direito Empresarial. Função Social. Ordem econômica. Justiça Social.

\begin{abstract}
In this article we intend to expose, analyze and understand the importance and viability of the activity and the exploration of business activity in consonance with the constitutional principles that deal with social function, social justice, valorization of human work, dignified existence and national social development. The study was carried out based on bibliographical research, using a technique in the examination of doctrines and scientific articles specialized in the subject and in the pertinent legislation. It was found that business activity, in general, has been occurring with the sole purpose of achieving profits; the particular interests of capital investors are placed above collective interests, which contributes to the increase of social inequality. This situation has been perpetuated in the mercantile environment many times due to lack of law enforcement in a strict way by the State.
\end{abstract}

Keywords: Business Law. Social role. Economic order. Social justice.

\section{INTRODUÇÃO}

A atividade empresarial é de suma importância, hodiernamente, pois é com base nela que se alcança o desenvolvimento local, regional, nacional e também internacional. Por essa razão, fez-se necessário a normatização, para regulamentá-la e organizá-la, tendo em vista a justiça e a igualdade, e para evitar o abuso econômico.

A Lei $\mathrm{n}^{\circ}$ 10.406, de 10 de janeiro de 2002 (Leia $\mathrm{n}^{\circ}$ 10.406/2002) dispõe que a atividade economicamente organizada se desenvolve pela produção e circulação de bens e serviços e deve objetivar não apenas a satisfação dos interesses do empresário, mas atender também os interesses da sociedade, o interesse coletivo.

A Constituição Federal de 1998 (CF/1988) trata da ordem econômica e financeira, com o objetivo de garantir atuação de acordo com os ditames da justiça social. A ordem econômica é norteada por fundamentos implícitos na valorização do trabalho humano e na livre iniciativa.

Assim, tais fundamentos e princípios orientam que a atividade econômica deve ser implementada e explorada, e, por conseguinte, alcançar a função social e o Estado, por outro lado, deve fiscalizar e intervir, quando necessário, para que tais princípios sejam respeitados e efetivados.

Ao longo desta pesquisa será discutida a importância da aplicabilidade do princípio da função social, do bem comum e da justiça social, em consonância com a atividade empresarial. Além disso, a magnitude dos princípios constitucionais, a viabilidade de sua aplicação e as consequências na distribuição de riquezas e progresso nacional.

\footnotetext{
${ }^{1}$ Graduanda em Direito pela Pontifícia Universidade Católica de Goiás, atua no programa de Monitoria pela PUC Goiás, é pesquisadora no Programa de Iniciação Científica da PUC Goiás. helensamarac@gmail.com

${ }^{2}$ Graduada em Direito e em Ciências Contábeis pela Pontifícia Universidade Católica de Goiás, especialista em Direito e Advocacia Empresarial, em Direito Educacional, em Análise e Auditoria Contábil, mestre em Gestão de Negócios com ênfase em controle de gestão, doutora em Educação com ênfase em políticas e gestão organizacional, com pós-doutorado em Ciências Jurídicas. helenabeatrizmb@hotmail.com
} 
O estudo foi realizado com base na metodologia de pesquisa qualitativa; fez-se o uso de técnicas de estudos em doutrinas especializadas no assunto, assim como em artigos científicos que tratam do tema; e, por fim, contou-se com o apoio de fontes primárias, quais sejam, os fundamentos legais.

\section{ATUAÇÃO DA EMPRESA FUNDADA NA JUSTIÇA SOCIAL E NO BEM COMUM}

Entende-se a atividade empresarial como um conjunto de atos que visam a produção ou circulação de um determinado bem ou serviço. No que diz respeito ao caráter econômico, este é definido pela capacidade de criar uma nova utilidade para determinado bem, lançando mão dos fatores de produção, de modo que esse bem possa ser oferecido ao consumidor, gerando, assim, lucro para o empresário. Não se pode esquecer que a atividade empresarial é exercida de forma organizada, coordenada e habitual, podendo variar de acordo com a especificidade de objeto.

O Estado atua para regular as obrigações e direitos daqueles que exercem a atividade empresarial, para que esta ocorra de forma justa e igualitária, para os indivíduos indistintamente. Nesse sentido, Coelho (2016, p.47) leciona que, "se não houvesse um regime jurídico específico para a exploração econômica, a iniciativa privada permaneceria inerte e toda a sociedade sofreria com a estagnação da produção dos bens e serviços indispensáveis"."

Como e verifica a CF/1988, em seu artigo 170, explicita que a ordem econômica é fundada na valorização do trabalho humano e na livre iniciativa. Para Mamede (2010, p. 40), tais princípios são "referências elementares e gerais que resultam da evolução da humanidade, ao longo da qual" desencadeia uma teoria jurídica, constituindo as metanormas de sustentação dos sistemas jurídicos.

A aplicabilidade de tais preceito permitem garantir uma existência digna de acordo com os ditames da justiça social, e, então, continua o Mamede (2010):

Essas referências marcam o Direito e influenciam sua existência e aplicação, mesmo quando não positivadas ou esmiuçadas pela lei, orientando, entre as múltiplas possibilidades de conteúdo que se podem atribuir a um mesmo texto normativo, aqueles que melhor amoldam ao Direito, aquelas que não o negam, além de suportar a colmatação de lacunas eventualmente detectadas (MAMEDE, 2010, P. 40).
Nesse sentido o autor argumenta sobre o alcance da justiça, para além da compreensão do Direito, tratado como se fosse somente uma reunião de regras positivadas com a reunião de constituições, leis, decretos, resoluções, portarias, circulares, dentre outras orientações normativas. Isto porque na colmatação de lacunas, nos casos em que houver falhas na legislação, inseguranças ou precariedade, deve o julgador colmata-las, portanto, constituindo significa a resposta da justiça com fundamentos no problema específico. São estas circunstâncias em que Mamede (2010) trata deste plano metanormtivo, constituído por princípios norteadores das decisões, nos casos de lacunas e impropriedades do ordenamento jurídico.

Retomando a materialização da atividade econômica, nota-se que a constituição brasileira aderiu ao liberalismo, pois deixa a cargo do particular a iniciativa do exercício de tais atividades. Merecem ressalva, todavia, algumas exceções em que o próprio Estado atua na atividade econômica (CF/1988, art. 173), deixando clara a função supletiva.

Nessa acepção, a justiça social e o bem comum são indispensáveis para que haja uma exploração da atividade econômica de forma justa e igualitária. A conceituação clássica de justiça foi produzida na cultura greco-romana. $O$ jurisconsulto Ulpiano (apud NADER, 2012, p.105) assim a definiu: "justitia est constans et perpetua volutas jus suum cuique tribuendi. (Justiça é a constante e firme vontade de dar a cada um o que é seu)". Desse modo, pode-se dizer que justiça é dar a cada um o que lhe é devido.

Nesse conceito, perceber-se a presença da alteridade, da sociedade como um todo, que pode ser compreendida como o papel, a obrigação de cada pessoa para a concretização da justiça e, consequentemente, a promoção do bem comum. Quando a justiça social não é observada, verificase um desequilíbrio social, com o domínio dos mais fortes em detrimento dos mais fracos.

Destarte, Montoro (2014) elucida que:

$\mathrm{Na}$ realidade, o que se verifica na luta pelos interesses individuais ou de grupos, se não for exigido o respeito a certos princípios de justiça, é o domínio dos mais fortes e o esmagamento dos mais fracos. As exigências do bem comum não podem ser deixadas ao livre jogo de interesses, nem a boa vontade dos indivíduos. Devem ser exigidos por lei, e constituir para os cidadãos um 
a obrigação estrita e exigível (MONTORO, 2014, p. 265).

Observa-se que a justiça social visa não somente a proteção dos menos favorecidos, mas a busca por uma distribuição equilibrada, igualitária e proporcional das riquezas. Pode-se citar, como exemplo, o justo salário cuja função é resguardar a dignidade dos trabalhadores, para evitar a sua desvalorização. "A justiça social observa os princípios da igualdade proporcional e considera a necessidade de uns e a capacidade de contribuição de outros" (NADER, 2012, p.112).

Justificam-se tais exigências para o cumprimento da justiça social e do bem comum a fim de inibir a arbitrariedade e o desequilíbrio econômico. $\mathrm{O}$ direito tem como alicerce a justiça, que é introduzida nas leis, passando a ser exigida da sociedade e aplicada nos tribunais, “(...) da mesma forma que o Direito depende da justiça para cumprir o seu papel, a justiça necessita ser corporificada nas leis, para se tornar prática. A simples ideia de justiça não é capaz de atender os anseios sociais" (NADER, 2012, p. 107).

Por derradeiro, vê-se que a finalidade da lei e o objeto da justiça social é o bem comum.

O bem comum é a noção complexa, em cuja composição entram vários elementos fundamentais, tais como a razão, a liberdade, justiça, ordem, paz, solidariedade, segurança, etc.: o bem comum não resulta da justaposição e sim da sintonização destes elementos (JAPPUR, 1992, p.42).

O bem comum, como se percebe, está fundado na existência digna da pessoa humana, tendo em vista suas necessidades, fundamentais para a própria subsistência da sociedade. A participação ativa de todos os membros da sociedade é indispensável para atender o benefício coletivo.

Dalto e Prates (2009, p. 24) argumentam que:

Dessa forma, é obrigação do empresário submeter todos os instrumentos da atividade empresarial ao crivo dos princípios constitucionais. Não só o estabelecimento empresarial (conjunto organizado de bens do empresário) deve cumprir uma função social, mas a própria atividade (empresa) deve ter por mote o respeito aos parâmetros da dignidade humana e social.

À vista disso, a atuação do empresário deve estar de acordo com o estabelecido constitucionalmente, para atender à justiça social, ao bem comum e, por conseguinte, à função social da empresa. O empresário não deve buscar apenas o lucro, mas, obrigatoriamente, atentar-se aos ditames constitucionais, levando em conta os interesses da sociedade.

\section{INFLUÊNCIA DA EMPRESA NO CRESCIMENTO SÓCIO-ECONÔMICO DO PAIIS}

A Constituição Federal de 1988 elencou uma série de direitos e deveres a serem respeitados, para que se possa organizar e resguardar a coletividade; de um modo geral, o empresário é responsável pelo desenvolvimento social e econômico, conforme dispõe o ordenamento jurídico brasileiro.

Constituir uma organização empresária é de livre iniciativa, sem restrições por parte do Estado, ressalvadas as exceções previstas em lei. É o que se observa na leitura da CF/1988, artigo 170, parágrafo único.

Percebe-se, assim, que o ingresso na atividade empresarial suscita, para o empresário, uma série de deveres a serem seguidos, tais como: prezar pela valorização do trabalho humano, assegurar a dignidade da pessoa humana, cumprir com a sua função social, garantir a livre concorrência, defender o consumidor e o meio ambiente.

O empresário possui, dessa forma, responsabilidades a cumprir, diante da sociedade, de modo a atender o interesse nacional, interesses estes que superam o intuito lucrativo. Boiteux (2002) argumenta que a responsabilidade empresarial tem sido percebida desde a década de 1920, dentre alguns grupos de empresários norteamericano influentes. Owen D. Young, principal executivo da General Eletric Company, citado pelo autor, comenta essa preocupação na época:

(...) Faz uma grande diferença em meu comportamento como um dos administradores da General Eletric Company saber se sou um 'trustee' da instituição ou um mandatário do investidor. Se sou um 'trustee', quem serão os beneficiários do meu esforço? Para quem eu devo minhas obrigações? Meu pensamento acerca do problema é o seguinte: há três grupos de pessoas que tem interesse na instituição. Um é o grupo representado por 50.000 pessoas que puseram capitais na companhia, isto é, os acionistas. Outro, o grupo de 100.000 pessoas que estão colocando sua força de trabalho e suas vidas nos negócios da companhia. O terceiro grupo é o dos consumidores e do público em geral. Os consumidores têm direito de reclamar que um negócio grande deva somente operar honesta e 
satisfatoriamente, mas que, além disso, deva ir ao encontro das suas obrigações públicas e cumprir seus deveres- que, em uma palavra, de sentido amplo, ela seja um bom cidadão (BOITEUX, 2002, p. 50).

Observa-se, na manifestação do executivo, a atenção especial aos trabalhadores e aos consumidores, vez que estes propiciam, diretamente, no sucesso de uma empresa. Entretanto, nos dias de hoje, tais valores vêm sendo respeitados precariamente em algumas organizações. Os interesses dos trabalhadores e dos consumidores, considerados alheios aos interesses da empresa, precisam ser respeitados, o que, na maioria das vezes, não ocorre. Tanto os interesses dos empresários como os interesses sociais merecem ser atendidos de forma harmônica.

Mamede (2010, p. 41) corrobora com esta assertiva ao afirmar que a livre iniciativa, pertinente as ações perpetradas por pessoas naturais ou jurídicas, são originadas com objetivos que vislumbram o alcance de vantagens econômicofinanceiras lícitas, independentemente se esses agentes sejam tipificados com empresário, empresa, sociedades (empresárias - tais como as sociedades limitadas e com o capital constituído por ações; ou simples em si, puras e impuras, bem como as cooperativas.

O ideal seria que a sociedade pudesse levar suas opiniões, interesses, de forma clara e de acordo com os anseios de cada região, diretamente à administração das empresas, para prevenir eventuais conflitos. Todavia, não há previsão no ordenamento jurídico neste campo, provocando várias ações na esfera judicial.

Não se pode olvidar que a atuação empresarial é importantíssima no que diz respeito ao meio ambiente, ameaçado pelos meios de produção que muitas vezes causam desastres irreversíveis, e que afetam a sociedade como um todo, inclusive as gerações futuras. A atividade econômica deve estar equilibrada com o meio ambiente de forma sustentável. Neste sentido Botelho e Moreno (2007) argumentam que:

[...] Estudos observaram que empresas que não melhoraram seu desempenho ambiental registraram uma perda estatisticamente significativa do valor de suas ações. Entre as perdas mais significativas relatadas, encontra-se o caso da Union Carbide, que perdeu $27,9 \%$ ou, aproximadamente, US\$ 1 bilhão do valor do mercado, por causa do acidente em Bhopal, enquanto a indústria como um todo perdem em média 1,28\% (BLACCONIERE; PATTEN, apud BOTELHO; MORENO, 2007, p. 204).

A exploração consciente dos meios de produção, aliada a investimentos positivos, como controle de poluição, propicia maior lucratividade e valorização dos negócios. Nos últimos tempos verificou-se que empresas envolvidas com a degradação, poluição ou rés em ações judiciais, por eventuais danos, violações ao meio ambiente, tiveram uma perda considerável do seu valor (BOTELHO; MORENO, 2007, p. 204).

Em meio aos mais variados interesses conflitantes têm-se a CF/1988, para equilibrar e servir de fundamentos ao poder do Estado. Tradase do "equilíbrio entre esse poder de agir e o dever de proteger os valores sociais do trabalho, igualmente preservados, como que a cumprir a função de limite para os abusos do capital" (MAMEDE, 2010, p. 41), vislumbrando, então, a equidade imprescindível, para permitir mecanismos indispensáveis ao processo decisório e o alcance da justiça social.

Outro ponto atinente à responsabilidade empresarial é a dignidade da pessoa que possui uma projeção histórica no ordenamento jurídico, tanto no plano interno (nacional) como no plano externo (internacional). Garantia fundamental e inerente a todo ser humano, de valor indivisível, visto que, quando ocorre uma lesão desta natureza, abrange a totalidade, não em partes.

Dado seu valor relevante, constitui dever do Estado promovê-la, garanti-la e respeitá-la de forma igualitária. Direito irreversível, inerente a todo ser humano, devendo permanecer enquanto houver eficácia e aplicabilidade no contexto social, em respeito ao princípio do não retrocesso, havendo a possibilidade de sua alteração no decorrer do tempo, para melhor atender os anseios sociais.

A empresa, independentemente de sua forma jurídica, possui uma função social, entendida como a capacidade do empresário de influenciar de algum modo o sistema econômico e a comunidade. Nesta perspectiva, Boiteux (2002, p. 56) arremata: "Que quando nos referimos à função social da empresa, portanto, estamos nos referindo a qualquer empresa, independentemente do seu porte, que possa ter impacto sobre o meio ambiente ou sobre a comunidade em que atua"."

A organização empresária é constituída por contrato social, e este, por conseguinte, deve abarcar a função social, com efeito entre os contratantes e sobre a sociedade. E, como 
contrato, deverá respeitar os princípios gerais próprios de tais documentos, como a probidade $\mathrm{e}$ boa-fé, e a aplicabilidade do artigo 421, do Código Civil de 2002 (Lei 10.406/2002), que dispõe: “ A liberdade de contratar será exercida em razão e nos limites da função social do contrato", possuindo, todavia, previsões específicas do direito empresarial, como a vedação de cláusula leonina (art. 1008, CC), constar expressamente as vantagens e desvantagens dos acionistas (art. $17 \mathrm{da}$ Lei no 6.404/76, Lei das Sociedades por Ações), e a necessidade de unanimidade dos sócios para realizar alterações no contrato (art. 999 e 997, CC/2002).

É perceptível a preocupação do legislador em garantir paridade entre as partes do contrato e terceiros, que, eventualmente, venham a participar dele. Como o Código Civil de 2002 previu, de forma taxativa, determinados tipos societários, cada um possui uma responsabilidade específica.

Ante o exposto, observa-se que a responsabilidade do empresário está intimamente ligada a uma série de regras e princípios gerais que devem ser respeitados, independentemente da forma jurídica adotada pelo empresário.

O diálogo entre as empresas e a sociedade civil é fundamental, no sentido de atender a certas exigências de determinados temas, como: preconceito, desigualdade econômica, corrupção, valorização dos trabalhadores e suas famílias etc., com o intuito de harmonizar o relacionamento entre a empresa e a coletividade, para que o país possa atingir um patamar ideal de desenvolvimento, tanto social e cultural como econômico.

\section{EXPLORAÇÃO ECONÔMICA E FUNÇÃO SOCIAL: CENÁRIO DE CONFLITOS}

O princípio constitucional da função social foi consagrado pela primeira vez na constituição Alemã Weimar de 1919, art. 153: que dizia: "A propriedade obriga. Seu uso deve, ao mesmo tempo, servir ao interesse da coletividade" (apud, DALTO, 2009, p. 21). No ordenamento jurídico brasileiro, a função social surgiu pela primeira vez na Constituição de 1967, com a emenda de 1969, disposta no art. 160, III que enunciava: “Art. 160. A ordem econômica e social tem por fim realizar o desenvolvimento nacional e a justiça social, com base nos seguintes princípios: III - função social da propriedade".",

O termo função deriva do verbo fungor, que significa realizar alguma coisa ou executar uma obrigação, de modo que seja assegurado o cumprimento de uma meta. De acordo com Dalton (2009, p. 18), a ideia de função social poderia ser extraída da obra de São Tomaz de Aquino, que afirmou que os bens adquiridos pelo homem teriam um fim em comum, que deveria ser respeitado. $\mathrm{O}$ autor completa citando Orlando Gomes, para elucidar que a função social consiste em um dever, em prol de outras pessoas.

De acordo com Dalto e Prates (2009, p.1819), a expressão função social foi difundida pelos teóricos Karl Renner e Léon Duguit no século XX. Para Renner, a função social estaria ligada aos processos econômicos da sociedade, a sua função econômica seria a função social do instituto jurídico. Nessa perspectiva, a função social residiria no fim em si do instituto jurídico. Nesse sentido, a função da empresa seria, por exemplo, a circulação de bens e serviços.

Ainda elucida o autor, por outro lado, que Léon Duguit, inspirado em Augusto Comte, esclarece que a solidariedade seria a essência dos fenômenos sociais. Segundo Duguit, o ordenamento não deveria proteger os direitos individuais do possuidor, cabendo a ele apenas positivar sobre a finalidade que o patrimônio deveria alcançar, atuando para a manutenção da estrutura social.

Para Comparato, citado por Dalto (2009), a função social envolve um poder-dever do proprietário, positivado pelo ordenamento jurídico. O poder corresponde à possibilidade de dar à propriedade o objetivo, o destino almejado. $O$ dever envolve a finalidade da destinação da propriedade, que deve visar o atendimento do interesse coletivo, não apenas o interesse do proprietário.

\footnotetext{
Mas a noção de função, no sentido em que é empregado o termo nesta matéria, significa um poder, mais especificamente, o poder de dar ao objeto da propriedade destino determinado, de vinculá-lo a certo objetivo. O adjetivo social mostra que esse objetivo corresponde ao interesse coletivo e não ao interesse próprio do dominus; o que significa que não possa haver harmonização entre um e outro. Mas, de qualquer modo, se se está diante de um interesse coletivo [...] corresponde a um poder-dever do proprietário, sancionável pela ordem jurídica (COMPARATO, apud, DALTO, 2009, p. 20-21).
}

A função social abarca, portanto, um direito subjetivo, que consiste em uma permissão dada pelo ordenamento jurídico, no sentido de poder dispor e gozar livremente da propriedade, 
juntamente com um dever imposto, caracterizado por um vínculo objetivo do qual o proprietário não pode se esquivar. Assim, o dever equivale à necessidade de dar uma destinação social à propriedade de acordo com o princípio da função social. Destarte, não se deve mentalizar a função social separada da utilidade social.

A CF/1988 trata da função social nos artigos $5^{\circ}$, inciso XXIII, $170,182, \S 2^{\circ}$ e no artigo 186. Entretanto, a Carta não faz alusão expressa à função social da empresa; daí o Conselho Nacional de Justiça Federal, durante a I Jornada de Direito Civil, elaborou o enunciado número 53, que expõe: "Deve-se levar em consideração o princípio da função social na interpretação das normas relativas à empresa, a despeito da falta de referência expressa" (apud PUPPIM, 2005, p. 15).

A função social da propriedade deve ser aplicada também no que concerne às normas do direito empresarial. Assim, a propriedade dos bens de produção deve ser utilizada conforme sua função produtiva, de modo a contribuir para o crescimento da nação, sem prejuízos aos interesses da coletividade.

A ordem econômica visa ordenar e coordenar as atividades produtivas, impondo condicionamentos à atividade econômica, com a intenção de evitar crises que circundam o sistema capitalista. Segundo Bulos (2010, p. 652), a ordem econômica, na realidade trata "de um microssistema normativo, integrado à própria carta constitucional positiva".

Tais diretrizes são, todavia um desafio, uma vez que a nossa sociedade adotou o modelo capitalista de produção cujo propósito é o lucro, e, por conseguinte, a acumulação e concentração de riquezas. Sistema que gera grande desigualdade social. De outro modo, o socialismo extremo aniquila a propriedade privada e limita as liberdades fundamentais. Daí, a presença do Estado na economia, como fiscalizador, intervindo, quando necessário, para que seja garantido o cumprimento das exigências da ordem econômica e da lei, de um modo geral.

Essa fiscalização, na concepção de Mamede (2010, p. 41) está implícita no equilíbrio declarado nos ditames constitucionais que prioriza a valorização da "coexistência harmônica entre o par dialético do trabalho e da livre iniciativa, elevados igualitariamente à condição de valores sociais"."

Por esse motivo, é fundamental que a empresa cumpra com sua função social, submetendo sua atividade aos princípios constitucionais, respeitando a dignidade humana e social. O empresário tem a obrigação de tratar com urbanidade seus próprios agentes, empregados, sócios e administradores, de modo a valorizar o trabalho humano, observando sempre as leis trabalhistas, impedindo que os trabalhadores sejam tratados de forma desumana, em respeito à soberania nacional, os consumidores, a livre iniciativa e a concorrência, e o meio ambiente, com vista a contribuir para a diminuição das desigualdades sociais.

A exploração da atividade empresarial consciente é imprescindível para o desenvolvimento nacional, entretanto, quando os lucros são postos acima da dignidade das pessoas, e o interesse particular se torna superior ao interesse público, ocorre o abuso econômico, cujo dever de reprimir cabe ao Estado.

Ao cumprir com sua função social, gerando empregos, automaticamente, a empresa proporcionará a circulação e distribuição de riquezas e promoverá o desenvolvimento social. Uma sociedade desenvolvida economicamente gera, por consequência, uma existência digna a seus habitantes. Se a sociedade se desenvolve, permitindo a distribuição efetiva de riquezas e igual oportunidade para todos, logo os indivíduos consumirão mais, o que resultará em benefício à exploração da atividade empresarial. Trata-se de uma reação em cadeia, todos ganham, a empresa, e a sociedade.

\section{CONSIDERAÇÕES FINAIS}

O presente estudo, cujo tema é recorrente, ensejou a compreensão da importância da atividade empresarial para o crescimento econômico e social do país. A aplicação das diretrizes constitucionais é indispensável para a efetividade da função social, da justiça social e do bem comum.

A atividade empresarial deve se expandir de acordo com os ditames e preceitos constitucionais, que garantem a existência digna e o desenvolvimento nacional. Assim, é imprescindível que o empresário e as organizações empresárias atuem em consonância com a justiça social, o bem comum, e também com a função social, para evitar arbitrariedades e desequilíbrio econômico.

O lucro deve ser visto como uma consequência da circulação de bens e serviços, não como objetivo primordial, atitude que contraria sua 
própria existência. O ideal é que os interesses dos empresários estejam em conformidade com os interesses coletivos.

A exploração da atividade empresarial é de livre iniciativa a todos que se interessem (desde que não haja impedimentos). Todavia, para exercêla, deve, primordialmente, cumprir com as responsabilidades e deveres, quais sejam, prezar pela valorização do trabalho humano, assegurar a dignidade da pessoa humana, cumprir com sua função social, garantir a livre concorrência, defender o consumidor e o meio ambiente.

Tais preceito e diretrizes, lamentavelmente, para alguns empreendimentos, estão apenas no plano teórico. Falta ainda sua devida aplicação por parte doa empresários e, ainda, atuação ostensiva por parte do Estado. Sem aplicabilidade, esses princípios serão apenas ideias que não passarão de declarações inócuas, daí tornase necessária a participação ativa de toda a sociedade, além dos próprios empresários.

A exploração da atividade empresarial deve ocorrer de forma consciente, justa e igualitária. Ao contrário, continuará a existir um crescente desequilíbrio econômico e desrespeito à dignidade da pessoa humana, a desvalorização do trabalhador, do consumidor e do meio ambiente.

\section{REFERÊNCIAS}

BOITEUX, Fernando Netto. A função social da empresa e o novo código civil. Revista de direito mercantil - industrial, econômico e financeiro, São Paulo, n.125, p.48-57, jan/mar. 2002.

BOTELHO, Tatiana; MORENO Roberto. A responsabilidade social e ambiental valoriza as empresas? Revista Direito, Estado e Sociedade. Rio de janeiro n. 31, 2007, p. 199- 219. Out. 2007

BRASIL. Constituição da República Federativa do Brasil, de 24 de janeiro de 1967. D.O.U 24 de janeiro de 1967. Disponível em: http://www.planalto.gov.br/ccivil_03/Constituic ao/Emendas/Emc_anterior1988/emc01-69.htm Acesso em: 17 agosto 2017.

BRASIL. Constituição da República Federativa do Brasil, de 5 de outubro de 1988. D.O.U. de $\mathbf{5}$ out. 1988. Disponível em: http://legislacao.planalto.gov.br/legisla/legislacao . Acesso em: 17, agosto 2017.

BRASIL. Lei $\mathrm{n}^{\circ}$ 10.406, de 10 de janeiro de 2002. Institui o Código Civil. D.O.U de $\mathbf{1 1}$ jan. 2002. Disponível http://www.planalto.gov.br/ccivil_03/leis/2002/ 110406.htm. Acesso em: Acesso em: 17 agosto 2017.

BRASIL. Lei n ${ }^{\circ} 6.404$ de 15 de dezembro de 1976. Institui a Lei das Sociedades por Ações. D.O.U de 15 de dez. 1976. Disponível em: http://www.planalto.gov.br/ccivil_03/leis/L6404 compilada.htm Acesso em: 17, Agosto 2017.

BULOS, Uadi Lammêgo. Direito Constitucional ao alcance de todos. 2.ed. ver. e atual de acordo com a EC n. 64, de 4-2-2010. São Paulo: Saraiva, 2010

COELHO, Fábio Ulhoa. Manual de Direito Comercial: direito de empresa. 28. ed. ver., atual., ampl. São Paulo: Editora Revista dos Tribunais, 2016.

CUNHA, José Ricardo Ferreira; VINICIUS, Scarpei. Os direitos econômicos, sociais e culturais: a questão da sua exigibilidade. Direito, Estado e Sociedade $_{s}$ Rio de Janeiro, n.31, p. 69-85, jul/dez. 2007.

DALTO, Hudson Augusto; PRATES, Saulo Hoffmann. A função social da empresa numa perspectiva civil constitucional. UNESC em revista, Colatina, v.11, n.25, p.12-31, jan. 2009.

DARCANCHY, Mara Vidigal. Responsabilidade social da empresa. ARGUMENTUM - Revista de Direito. Marília, v. 7, jan/dez. 2007.

JAPPUR, José. O bem comum. Instituto dos Advogados do Rio Grande do Sul, Porto Alegre, v.7, n.18, p.41-43, maio/dez. 1992.

MAMEDE, Gladston. Direito empesaria brasileiro - empresa e atuação empresarial. 4. ed. São Paulo: Atlas, 2010.

MONTORO, André Franco. Introdução à ciência do direito. 31. ed. rev. e atual. São Paulo: Editora Revista dos Tribunais, 2014.

NADER, Paulo. Introdução ao estudo do direito. 34. ed. Rio de Janeiro, 2012.

OLIVEIRA, Fabrício de Souza. Anotações sobre a função social da "empresa". Revista da Faculdade de Direito Milton Campos, Belo Horizonte, v.13, n.13, p.161-174, jan/dez. 2006.

PUPPIM, Alexandre. A função social da empresa: uma nova perspectiva para o Direito Empresarial. Revista do Direito. Faculdade de Direito de Cachoeiro de Itapemirim (FDCI). 
Cachoeiro de Itapemirim, v.5, n.5, p. 13-25, maio 2005. 